\title{
Predicting regeneration of physical damage on a reef-building coral by regeneration capacity and lesion shape
}

\author{
Erik H. Meesters ${ }^{1,2,3, *}$, Werner Pauchli ${ }^{1,2}$, Rolf P. M. Bak ${ }^{2,3}$ \\ ${ }^{1}$ Caribbean Marine Biological Institute, Carmabi, PO Box 2090, Curaçao, Netherlands Antilles \\ ${ }^{2}$ Institute of Systematics and Population Biology, PO Box 94766, University of Amsterdam, 1090 GT Amsterdam, The Netherlands \\ ${ }^{3}$ Netherlands Institute for Sea Research (NIOZ), PO Box 59, 1790 AB Den Burg, The Netherlands
}

\begin{abstract}
We present a relationship that predicts regeneration of physical damage on reef-building corals as a function of regeneration capacity and lesion shape. The great abundance of lesions on colonies in the field and the characteristics of the regeneration process indicate that the ability of corals to regenerate damage is limited. Regeneration, the extension of new coral tissue over a damaged area, slows down exponentially. We: hypothesized that regeneration is a function of (1) a species specific regeneration capacity and (2) the amount of tissue that directly borders a lesion. A corollary is that there should be a maximum amount of tissue that can be recovered for a certain amount of border. Consequently, there is a maximum lesion size that can be completely regenerated by the surrounding tissue depending on the shape of the lesion. We studied the regeneration process in field experiments and made circular lesions of 4 different size classes $\left(83,183,243\right.$ and $\left.406 \mathrm{~mm}^{2}\right)$ on colonies of the main reefbuilding coral of the Caribbean, Montastrea annularis. Lesion size decreased rapidly at the onset of the regeneration process but the rate of regeneration slowed to zero and the curve representing lesion size with time approached an asymptote. This asymptote represents the size of the area which is not recovered by the regenerating tissue at the end of the regeneration process. The value of this asymptote increased with increasing lesion area, indicating limited regeneration capacity. Larger lesions regenerated more tissue than smaller lesions, but this difference was absent when the regenerated surface area was standardized to initial lesion perimeter This indicates that the lesion perimeter is the primary factor determining the amount of area that will be regenerated. $M$. annularis could regenerate a maximum of $4.7 \mathrm{~mm}^{2}$ of new tissue per $\mathrm{mm}$ of lesion perimeter length. Circular lesions larger than $130 \mathrm{~mm}^{2}$ will not be regenerated. The dependence of regeneration on lesion perimeter results in lesion shape being of major importance for the degree of regeneration of physical damage (e.g. long narrow lesions may be closed, while circular lesions of much smaller size may never be closed). A relationship is presented that predicts percentage regeneration on the basis of lesion shape, with shape being defined as the ratio of initial lesion surface area to initial perimeter length. This function predicts regeneration of physical damage in $M$. annularis for any size and shape of lesion.
\end{abstract}

KEY WORDS: Regeneration - Lesions Shape Size Damage Corals Restoration Patch

\section{INTRODUCTION}

When the living tissue of a coral colony has been damaged, the surrounding polyps and coenenchym respond by regenerating new tissue (Fishelson 1973).

\footnotetext{
-Address for correspondence: Netherlands Institute for Sea Research (NIOZ), PO Box 59, 1790 AB Den Burg, The Netherlands. E-mall:erikm@nioz.nl
}

Initially, tissue regeneration is very fast, but it slows down exponentially (Bak 1983). During the first week of the regeneration process, most new tissue is undifferentiated; polyps begin to develop in the second week (Meesters \& Bak 1995). Different species vary in their capability for regeneration (Bak 1983, Meesters et al. 1992, Bak \& Meesters 1996). In rapidly regenerating species, lesions may be fully closed by undifferentiated tissue before new polyps can be observed, while other 
species regenerate so slowly that polyps develop almost simultaneously with the progress of the new tissue layer (Meesters \& Bak 1995). The regeneration rates of different species are influenced to varying degrees by environmental stresses, such as temperature related bleaching (Meesters \& Bak 1993) and sedimentation (Meesters et al. 1992), probably through their demand on the organism's energy requirements. Regeneration affects growth (Meesters et al. 1994) and reproduction (Van Veghel \& Bak 1994), indicating that the process is deeply interwoven with species' life history strategies. Because regeneration capability forms an integrated measure of the physiological condition of a coral (Meesters et al. 1992, 1994, Meesters \& Bak 1993), it has been proposed as a tool for assessing the health condition of coral populations (Meesters \& Bak 1994).

Field observations indicate that the regeneration of damage is often incomplete and the living tissue of coral colonies appears littered with multiple open patches or lesions that have become colonized by other organisms (Meesters et al. 1996, 1997). These patches represent partial mortality, an important phenomenon in modular and clonal organisms, such as reef-building corals, influencing life history processes such as growth, reproduction, and regeneration (Jackson 1979, Hughes \& Jackson 1980, Jackson \& Coates 1986, Hughes 1989, Hughes et al. 1992). Many coral populations may lose more living cover through chronic partial mortality than through large sporadic disturbances such as hurricanes (Hughes \& Jackson 1985, Bythell et al. 1993), even though natural recruitment and growth may be sufficient to give the impression of an apparently stable population (Bak \& Luckhurst 1980).

Permanent lesions on coral colonies may indicate that the regeneration capacity of corals is limited. Bak \& Steward -van Es (1980) showed that lesions larger than $5 \mathrm{~cm}^{2}$ were seldom fully regenerated. Furthermore, energy for regeneration appeared to be originating from an area around the lesion that was only $6 \mathrm{~mm}$ wide (Meesters et al. 1994). This means that convoluted lesions, having much more perimeter per surface area then, for example, round lesions, will have a higher chance of becoming fully regenerated. Lesion shape will then determine whether a lesion will be closed. We hypothesize that regeneration capacity in corals is limited and dependent on the length of tissue along the perimeter of the lesion. This means that for any shape of lesion there will be a maximum amount of tissue that can be regenerated by the surrounding tissue.

The objective of this study was to determine the maximum lesion size that can be regenerated by the surrounding tissue. We present data for the main Caribbean reef-building coral Montastrea annularis
(Ellis and Solander) and develop a model that predicts the regeneration of lesions of any size and shape.

\section{MATERIALS AND METHODS}

Twenty-five colonies of the Columnar Morphotype of coral Montastrea annularis (Elis and Solander) (Van Veghel \& Bak 1993, or $M$. annularis after Knowlton et al. 1992) were selected haphazardly at Carmabi buoy 2 on the southwestern coast of the island of Curaçao, Netherlands Antilles, at a depth of 4 to $6 \mathrm{~m}$. These fringing reefs have been described in detail by Bak (1977) and Van Duyl (1985).

Selected colonies consisted of at least 4 columns that shared a common base and that were not connected by living tissue. To reduce variation resulting from genetic differences between colonies, the experiment was set up as a randomized complete block design (Sokal \& Rohlf 1981), each colony receiving 4 circular lesions of different size, 1 per randomly selected column (20 October 1992). Average radii (standard deviation, SD) of the 4 lesion size classes were $3.6(0.2), 6.1$ $(0.3), 7.3(0.3)$, and $9.6(0.3) \mathrm{mm}$. Lesions were made with small grinding stones attached to a pneumatic drill powered by a SCUBA tank. Average lesion depth (2.5 $\mathrm{mm}$ ) was the same for all lesion size classes [1-way analysis of variance (ANOVA), $F_{3,96}=1.3, p=0.27$ ]. Average total initial lesion surface area ( $S D, n=25$ for each group) amounted to 83 (12), 183 (20), 243 (16), and $406(34) \mathrm{mm}^{2}$. This includes the surface area of the wall of the lesion. Tissue regeneration in the lesions was followed by measuring lesion size with a plexiglass ruler divided into $2 \mathrm{~mm}$ squares at $2,4,8,15,22$, $29,36,50$, and 64 d after lesion infliction.

Data for each lesion were fitted to the non-linear function

$$
\text { Size }=\text { Asymp. }+\left[\text { Size }_{\text {reg }} \times 10^{\text {(sione } \times \iota)}\right]
$$

in which: Size = lesion surface area in $\mathrm{mm}^{2}$; Asymp. = asymptote, the area that is not regenerated when the regeneration rate has decreased to zero; Size $_{\text {reg. }}=$ the area that can be fully regenerated; slope = the regression slope; $t=$ time in days.

This model is basically a modification of the equations of von Bertalanffy (1957) describing regeneration in terms of an exponential decrease in lesion size to a potential asymptote (Meesters et al. 1994, Meesters \& Bak 1995). The non-linear iterative fitting method used the above function and the Simplex least-squares method (Wilkinson 1989).

Differences in variable means among lesion size classes were tested by ANOVA. Assumptions (i.e. homogeneity of variances, and normality and independence of error terms) were checked by residual plots 
and the data were transformed if necessary. Pairwise comparisons were carried out using the Bonferroni test. All statistical analyses were performed with the program Systat (Wilkinson 1989).

\section{RESULTS}

Regeneration differed greatly among the 4 size groups (Fig. 1). After $64 \mathrm{~d}, 67 \%$ of the lesions in the smallest size class $(n=24)$ were closed, while in the other groups less than $10 \%$ had closed $\left(\chi^{2}=33.3\right.$, $\mathrm{df}=3, \mathrm{p}<0.0001)$. Apparently, there is a strong decrease in the chances of full recovery between 83 and $183 \mathrm{~mm}^{2}$ Field observations on very small lesions suggest that most of the lesions in the smallest size class that had not been regenerated at the end of the experimental period would close as well, because their remaining size was less than $4 \mathrm{~mm}^{2}$.

During the $64 \mathrm{~d}$ of the experiment 8 of the total of 100 lesions were influenced by external agents, and subsequently removed from further analyses. Of these 8 , the area around one became bleached and regeneration appeared slower than in the rest of the lesions (see also Meesters \& Bak 1993). The other 7 lesions had been enlarged, probably by activities of fish. The discrepancy between the remaining 92 lesions and the number in Fig. 1 is due to the fact that at the end of the experimental period 4 lesions could not be traced, probably because they had been completely regenerated, including regaining of original coloration

Lesion size followed an exponential decrease through time (Fig. 2): at first, the rate of regeneration was high and lesion size decreased relatively quickly, however, after the first week, the regeneration rate slowed rapidly and lesion size decreased more slowly. The differences in the regeneration rate during the first and last measuring interval show this clearly (Table 1)

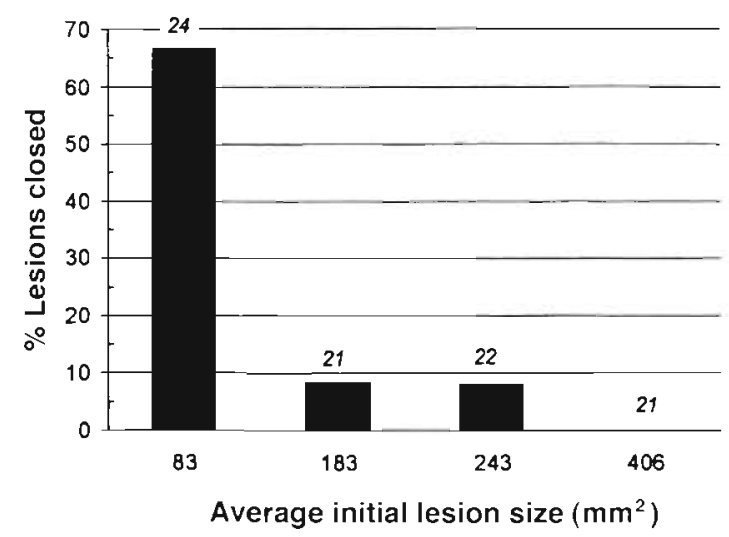

Fig. 1. Montastrea annularıs. Percentage of lesions closed after $64 \mathrm{~d}$ in the 4 lesion size classes (indicated by their initial sizc). Total number of lesions measured shown on top of columns

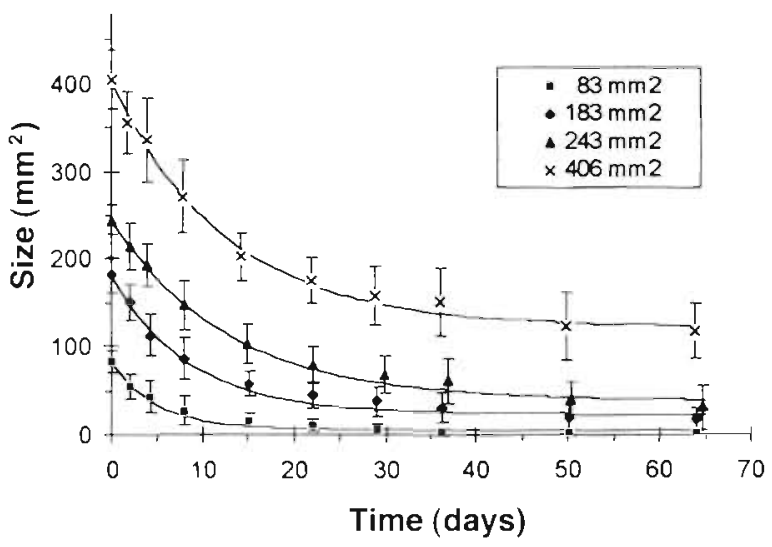

Fig. 2. Montastrea annularis. Average lesion size $( \pm \mathrm{SD})$ through time for the 4 groups ( $n=21$ to 25 at each data point). Lines connecting data points are averages of least squares estimation of Size $=$ Asymp. $+\mid$ Size $_{\text {tey }} \times 10^{\text {islope }} \times$ " $\mid$, see 'Materials and methods'

Table 1. Montastrea annularis. Geometric mean regeneration rate and confidence limits (CL) from Days 0 to 8 and from Days 50 to 65 . Statistical differences between lesion size classes (ANOVA incomplete block design): Days 0 to 8 , $p<0.001, F_{3.64}=55.2 ;$ Days 50 to $64, p=0.12, F_{3.54}=2.1$

\begin{tabular}{|lccc|}
\hline $\begin{array}{l}\text { Initial size } \\
\left(\mathrm{mm}^{2}\right)\end{array}$ & $\begin{array}{c}\text { Mean regeneration } \\
\text { rate }\left(\mathrm{mm}^{2} \mathrm{~d}^{-1}\right)\end{array}$ & $95 \% \mathrm{CL}$ & $\mathrm{n}$ \\
\hline $\begin{array}{l}\text { Days 0 to 8 } \\
83\end{array}$ & 6.71 & $6.09 / 7.39$ & 25 \\
183 & 11.51 & $10.40 / 12.73$ & 22 \\
243 & 11.51 & $10.40 / 12.73$ & 22 \\
406 & 15.99 & $14.45 / 17.70$ & 23 \\
Overall & 10.79 & $10.26 / 11.35$ & 92 \\
Days 50 to 64 & & & \\
83 & 0.09 & $-0.30 / 0.50$ & 24 \\
183 & 0.13 & $-0.30 / 0.59$ & 21 \\
243 & 0.70 & $0.26 / 1.16$ & 22 \\
406 & 0.53 & $0.07 / 1.01$ & 21 \\
Overall & 0.35 & $0.15 / 0.56$ & 88 \\
\hline
\end{tabular}

During the last interval tissue regeneration almost ceased, especially in the 2 smallest lesion sizes. Regeneration rate was $0.35 \mathrm{~mm}^{2} \mathrm{~d}^{-1}, 3.2 \%$ of that of the first week. After the first week, regeneration differed significantly ( $p<0.001$ ) among the 4 size classes (Table 1 ). but at the end of the observation period (64 d) all classes regenerated at similar rates $(p=0.12)$

\section{Model estimates}

The regression lines that resulted from the nonlinear fitting described the regeneration process very well (Fig 2). All estimated model parameters (Table 2) differed significantly between the 4 groups. 
Table 2. Montastrea annularis. Geometric mean (lower/upper $95 \%$ confidence limits) of estimates resulting from fitting data from each lesion to the non-linear function Size $=$ Asymp $+\left[\right.$ Size $_{\text {ren }} \times 10^{\text {tslope }} \times$ "I $]$. All size data in $\mathrm{mm}^{2}$ Asymp. (the asymptote): the lesion area that was not regenerated; Size $_{\text {reg }}$ the regenerated area; slope: the regression slope; $T_{\text {asymm }}$ : number of days to reach asymptote $\left(+1 \mathrm{~mm}^{2}\right)$

\begin{tabular}{|lcccc|}
\hline Initial size $\left(\mathrm{mm}^{2}\right)$ & - Slope & Asymp. & Size $_{\text {reg }}$ & $T_{\text {asymp }}$ \\
\hline 83 & 0.076 & 5.9 & 80.2 & 24.7 \\
& $(0.065 / 0.088)$ & $(4.8 / 7.3)$ & $(75.4 / 85.3)$ & $(19.9 / 30.5)$ \\
183 & 0.048 & 19.2 & 164.8 & 45.3 \\
& $(0.041 / 0.057)$ & $(15.6 / 23.7)$ & $(154.9 / 175.3)$ & $(38.7 / 53.0)$ \\
243 & 0.032 & 34.7 & 209.9 & 71.6 \\
& $(0.028 / 0.038)$ & $(28.1 / 42.3)$ & $(196.4 / 224.4)$ & $(61.8 / 83.0)$ \\
406 & 0.033 & 121.1 & 283.8 & 72.9 \\
& $(0.029 / 0.039)$ & $(98.7 / 148.5)$ & $(261.8 / 307.7)$ & $(66.0 / 80.6)$ \\
Significance & $p<0.001$ & $p<0.001$ & $p<0.001$ & $p<0.001$ \\
between groups & & & & \\
\hline
\end{tabular}

between the 2 largest lesion sizes $(p=0.989)$. This means that for the 2 largest lesion sizes the relative decrease in lesion size per unit of time was the same. The actual decrease depends on the initial lesion size. The absence of a significant difference between the 2 largest lesion sizes supports the hypothesis that regeneration capacity is limited and the regression slope approaches an asymptote as initial lesion size increases. Using the same non-linear function as for lesion size (Fig. 2), we calculated that the regression slope has a maximum value of -0.18 and an asymptote of -0.033 (Fig. 3).

\section{Regression slope}

The slopes of the exponential regression lines differed among the 4 lesion size classes (Tabie 2; $F_{3,91}=28.5, \mathrm{p}<0.001 ; 1$-way ANOVA with the regression coefficient log transformed). The slope was steepest in the smallest lesions, least steep in the 2 largest lesions and intermediate in the second smallest group. Thus, lesion size decreased fastest in the smallest lesions and slowest in the 2 largest groups

The regression slope was dependent on the initial lesion size (Fig. 3). Post hoc pairwise comparisons (Tukey HSD) differed significantly $(p<0.01)$, except

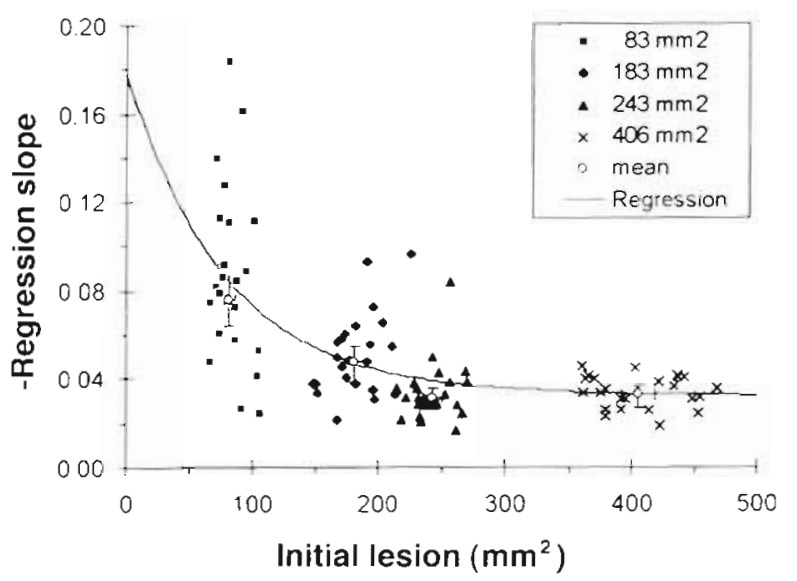

Fig. 3. Montastrea annularis. Estumated regression slope and unitial size for each lesion. Also shown are the means $( \pm 95 \%$ confidence limits) of each lesion size class. Estimated regres-

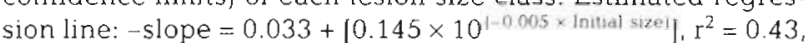
$\mathrm{p}<0.001, \mathrm{n}=92$

\section{Asymptote}

The lesion surface area that remained bare after regeneration ceased, indicated by the asymptote level, increased with increasing initial lesion size (Fig. 2, Asymp. in Table 2). Mathematically, the exponentially decreasing functions (Fig 2) never reach the asymptotic value. However, by assuming that regeneration will almost have ceased at a slightly larger size $\left(+1 \mathrm{~mm}^{2}\right)$, we can calculate the approximate length of time to reach the asymptotic level. The length of time before the asymptote was reached ( $T_{\text {asymp }}$ in Table 2) and regeneration speed had decreased to zero also increased with lesion size and differed significantly among the 4 groups $\left(F_{3,67}=65.4, p<0.001\right.$; 1 - way ANOVA with time square root transformed). This difference was not significant between the 2 larger size classes ( $p=1$, Bonferroni pairwise comparisons), both of which reached an asymptote after about $72 \mathrm{~d}$.

\section{Model accuracy}

The model used to describe lesion regeneration was extremely accurate with coefficients of determination for the lesions $\left(\mathrm{r}^{2}\right)$ ranging from 0.91 to 0.99 . Even so, some minimal errors were observed.

The estimated asymptotic value often $175 \%$ of the cases) appeared to be slightly larger than the actual lesion size after $64 \mathrm{~d}$. This overestimation was calculated (estimate minus real value) to be on average $5.4 \mathrm{~mm}^{2}(\mathrm{SD}=1.2)$ and did not differ amoung the 4 groups (ANOVA, $F_{3,84}=46.3, \mathrm{p}=0.76$ ). Of the estimates, $95 \%$ were still within $8 \mathrm{~mm}^{2}$ of the real size.

The sum of the estimated asymptote and Size $_{\text {req. }}$ (Table 2) should equal the initial lesion size. When we 
compared [Initial size - (Asymptote + Size $_{\text {reg. }}$ )], we found no difference amoung the 4 size classes (ANOVA, $F_{3,91}=2.3, p=0.08$ ). The average difference between real and estimated initial size with the 4 groups combined was $1.75 \mathrm{~mm}^{2}$ (SE $=0.89, \mathrm{n}=91$ ).

\section{Total area recovered}

Larger lesions regenerated more area, but the rate of increase diminished as lesion size increased (Fig. 4). At the end of the experiment, the average total regenerated area from the smallest to the largest size class was $80,165,210$, and $284 \mathrm{~mm}^{2}$ (all Tukey pairwise comparisons, $\mathrm{p}<0.001$ ) Note in Fig. 4 how the number of lesions that were fully closed at $64 \mathrm{~d}$ decreases with increasing lesion surface area. In the smallest size class, most lesions are on or very close to the $100 \%$ regeneration line, while at increasing lesion size more lesions remain open and are further distanced from this line. As lesion size increases, the relative amount of area that is regenerated, decreases. This indicates that the capacity for regeneration is limited.

If the regenerated area is standardized to the length of initial lesion perimeter (Fig. 5), the 3 larger lesion size classes recovered similar amounts of tissue (Tukey pairwise comparisons, $p>0.1$ ). The smallest size class regenerated significantly less area than the 2 largest classes $(p<0.0001)$.

We calculated that the maximum area that can be regenerated by $1 \mathrm{~mm}$ of lesion border tissue in Montastrea annularis is 4.7 (confidence limits $4.47 / 4.86$ ) $\mathrm{mm}^{2}$ (regression line in Fig. 5). This means that the tissue around the smallest lesions could have regenerated an area of

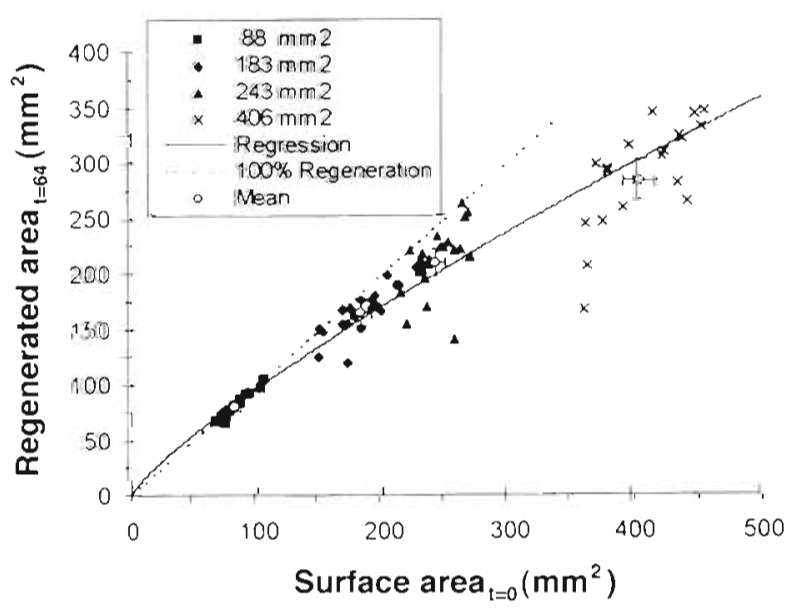

Fig. 4. Montastrea annularis. Total area regenerated after $64 \mathrm{~d}$ and initial lesion size for each lesion. Dashed line represents total regeneration of lesion. Regression line: Area $t=64=$ 2.31 (Initial size) ${ }^{0812}, \mathrm{p}<0.001, \mathrm{r}^{2}=0.95, \mathrm{n}=88$. Means $\{ \pm 95 \%$ confidence limits) of each lesion size class are also shown

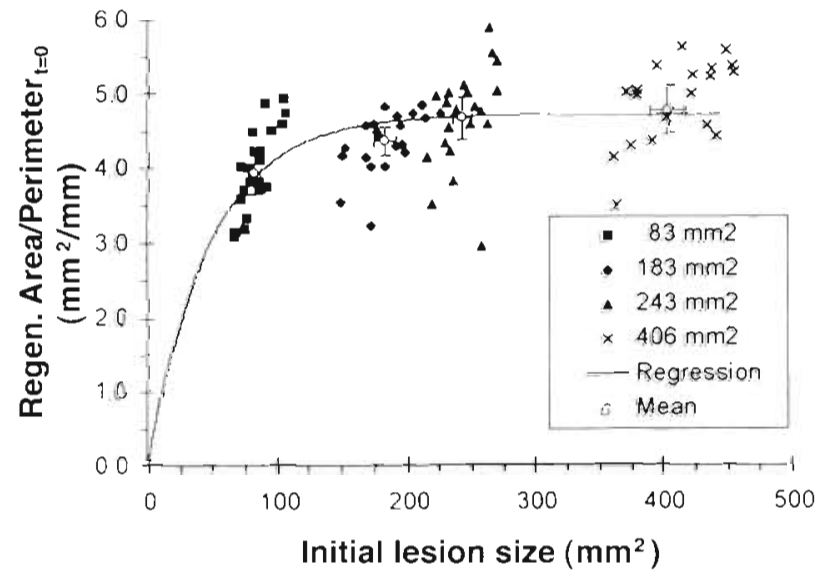

Fig. 5. Montastrea annularis. Total regenerated area per initial length of lesion perimeter and initial lesion size. Also shown are the means ( $\pm 95 \%$ confidence limits) of each lesion size class. Estimated regression line: Area ${ }$ / Perimeter $_{\mathrm{r}=0}=4.7-\left[4.7 \times 10^{1-0.009 \times \text { Imital size }^{2}}\right], \mathrm{r}^{2}=0.31, \mathrm{n}=88$

approximately $98 \mathrm{~mm}^{2}$ (average perimeter $20.8 \mathrm{~mm}$ ). Because their mean size was only $83 \mathrm{~mm}^{2}$, these lesions were closed before the full regeneration capacity was reached, explaining why the mean area recovered per $\mathrm{mm}$ lesion perimeter is lower than in the other size classes. The mean of the second size class $\left(183 \mathrm{~mm}^{2}\right)$ also reflects this, but to a lesser (non-significant) degree.

\section{Lesion shape}

Because lesion regeneration appears to depend directly on the length of living tissue bordering the lesion, the shape of a lesion will determine lesion closure. Lesions that have a smaller area to perimeter ratio will be regenerated more than lesions that have relatively less perimeter. Using the average lesion depth of this study, $2.5 \mathrm{~mm}$, we calculated that the maximum size of a circular lesion that will be fully regenerated is approximately $1.3 \mathrm{~cm}^{2}$ in Montastrea annularis $\left[2 \pi r \times 4.7=\pi r^{2}+(2 \pi r \times 2.5)\right]$. We also calculated a relationship (for the circular lesions in this study) that predicts the degree of lesion regeneration: $\arcsin (\%$ Regenerated area $/ 100)=1.6-(0.00145 \times$ Initial lesion area), $\mathrm{r}^{2}=0.63, \mathrm{p}<0.001, \mathrm{n}=88$

Lesions of a circular shape, used in this study for logistical reasons, are however only a very restricted group within the whole range of lesion shapes that can be found in the field. Some will be circular, but most will have very different shapes and one would predict that a linear lesion will heal much faster than a circular lesion of the same surface area, because there is much more tissue bordering the linear lesion (Fig. 6).

The shape of a lesion can be expressed by the ratio of surface area to perimeter length. Because the lesions 


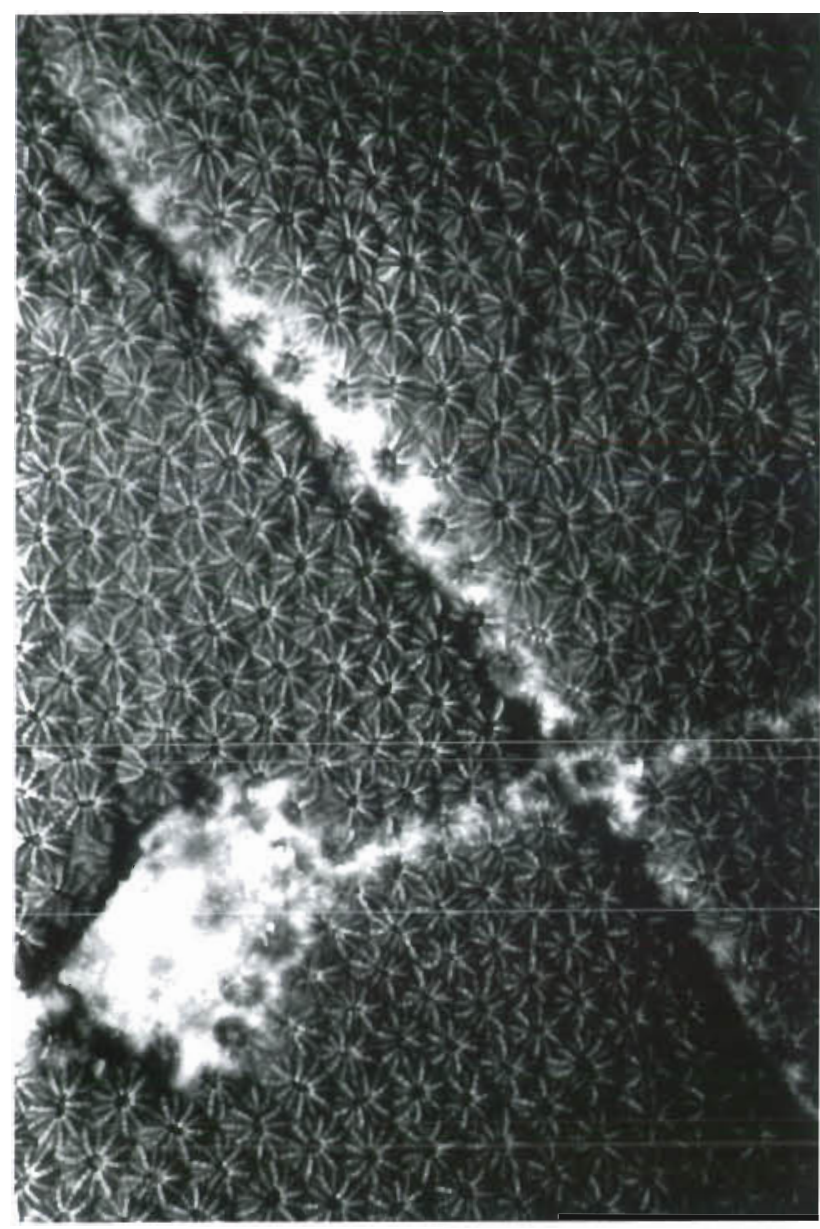

Fig. 6. Montastrea annularis. Photograph illustrating the importance of lesion perimeter. Regeneration after 2 wk of 1 circular (app. $2 \mathrm{~cm}^{2}$ ) and 2 linear artificial lesions on 1 colony inflicted at the same time. Note how linear lesions are already completely covered by tissue

that we used were of different sizes, they have different area/perimeter ratios, even though having the same shape. Consequently, a relationship can be calculated that predicts regeneration for lesions of any size and shape, using the ratio of initial lesion surface area to the length of initial lesion perimeter (Fig 7).

\section{DISCUSSION}

\section{Regeneration capacity}

The results of this study indicate that the regeneration capacity of living coral tissue is limited. Small lesions have a high chance of full recovery, while larger lesions have less chance (Fig. 1). Between 83 and $183 \mathrm{~mm}^{2}$ the chances of full recovery drop sharply. Previous authors (e.g. Loya 1976) assumed that a large

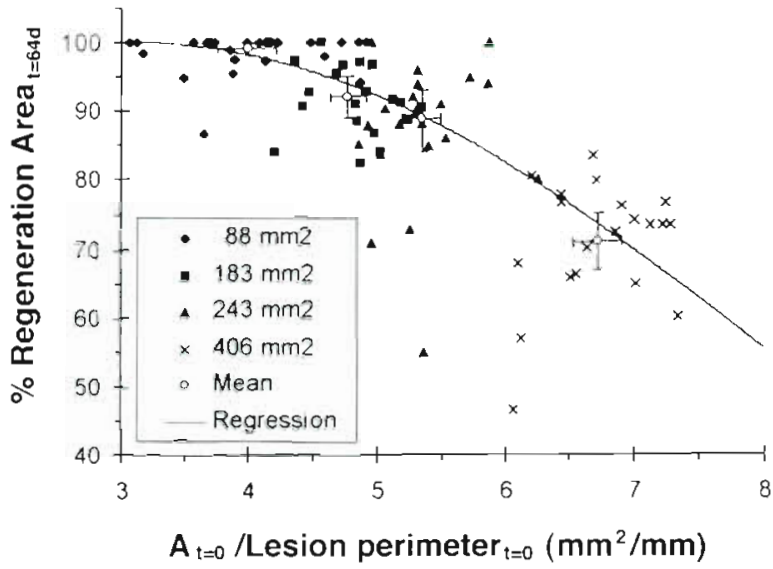

Fig. 7. Montastrea annularis. Percentage regeneration and the ratio of inttal lesion surface area $\left(A_{t=0}\right)$ and initial lesion perimeter length of each lesion. Regression line: $\arcsin (\%$ Regeneration $)=2.032-\left(1.49 \times A_{t=0} /\right.$ Perimeter length $), p<$ $0.001, r^{2}=0.55, n=88$. Also shown are the means and $95 \%$ confidence limits of each size class

part of the colony supplied the energy for regeneration. Meesters et al. (1994) caiculated that the energy for lesion regeneration could have been produced by a band of tissue of only $6 \mathrm{~mm}$ width. They hypothesized that, if regeneration is primarily fueled by a small band of tissue along the perimeter of the lesion, the ratio of regenerated area to lesion perimeter length would be the same, regardless of the initial size of the lesion.

In this study we show that this is true for lesions that are too large to be completely regenerated the area that was regenerated by the living tissue was equal in lesions of different size when standardized to the initial lesion perimeter length (Fig. 5). If lesion size is smaller than the maximum area that can be regenerated, the amount of tissue regenerated per length of lesion perimeter will be smaller (Fig. 5). In Montastrea annularis, for each $\mathrm{mm}$ of tissue along the lesion perimeter, approximately $4.7 \mathrm{~mm}^{2}$ can be regenerated.

Because lesion perimeter length determines the amount of tissue that can be regenerated, lesion shape is more important than lesion size with regard to the degree of regeneration of physical damage. For example, the surface area of a lesion can be greater than any of the artificial lesions in this study and still be completely regenerated, provided that the lesion is very narrow, because $1 \mathrm{~mm}$ of lesion perimeter tissue can grow inward approximately $4.7 \mathrm{~mm}$ (Fig. 5). As long as the width of a lesion does not exceed approximately 1 $\mathrm{cm}$, the chance that it will be closed will be around $100 \%$. This means also that the chances of lesion recovery are related to both the size and the total perimeter of the lesion. The ratio of patch surface area to patch perimeter length has been proven to be a useful index for patch shape in benthic ecology (Sousa 
1984, Connell \& Keough 1985). Analogous to this ratio we show that the ratio between lesion surface area and lesion perimeter length can be used to predict the degree of regeneration of any lesion (Fig. 7). Only $2 \%$ of the lesions with a ratio above $5(n=1)$ were fully regenerated, whereas $41 \%$ of the lesions with a ratio below 5 were fully recovered.

Regeneration of small lesions can be very rapid. In this study the first lesions were closed after $22 \mathrm{~d}$, but very small and/or narrow lesions (small area/perimeter ratio), can be closed within a few days (author's pers. obs.). Using the function shown in Fig. 3 we can estimate the slope and time before closure of very small circular lesions. For example, a lesion of only $10 \mathrm{~mm}^{2}$ would on average be fully regenerated within 6 to $7 \mathrm{~d}$ (estimated slope -0.162 ).

An assumption of this study is that no living tissue remains within the lesion after infliction and that regeneration can only occur from the side of the lesion. In Montastrea annularis, lesions need to be approximately $2 \mathrm{~mm}$ deep to remove all tissue (in this study average lesion depth was $2.5 \mathrm{~mm}$ ). Shallower lesions would regenerate much faster than estimates in this study, because tissue would not only be regenerated from the side, but also from tissue remains within the lesion.

Meesters et al. $(1996,1997)$ showed that lesions smaller than $1 \mathrm{~cm}^{2}$ represented approximately $40 \%$ of all lesions on coral colonies at Curaçao reefs. Because this study shows that Montastrea annularis completely regenerates lesions smaller than $1 \mathrm{~cm}^{2}$, these lesions were initially probably larger than the maximum regeneration capacity. Size frequency distributions of natural lesions on coral colonies were highly skewed to the right (Meesters et al. 1996, 1997), indicating that the infliction rate of small lesions must be very high, particularly as a large part of the smaller lesions should be regenerated. Consequently, the living tissue of coral colonies should be extremely dynamic: tissue removal occurring at high rates being countered by tissue repair at almost equally high rates. Tissue turnover rates, the time necessary to replace the entire initial surface area in $M$. annularis populations, have been estimated at 15 yr (Bythell et al. 1993) and 36 yr (Bak \& Luckhurst 1980). We suggest that in reality these turnover rates are much faster, because most lesions are so small that they will be regenerated within a time period that is shorter than the time interval between 2 observations.

\section{Evolutionary reasons for limited regeneration capacity}

Because most coral colonies display partial mortality, it appears that the coral would benefit from a higher regeneration capacity. Limiting regeneration capacity to small lesions may be most efficient if there are tradeoffs between other vital processes, such as growth and reproduction. The combination of time and effort required for the regeneration of large lesions may represent too much of a loss in terms of energy. Regeneration costs energy that is taken from other processes such as growth and reproduction (Meesters et al. 1994, Van Veghel \& Bak 1994). Meesters et al. (1994) estimated that a lesion of $8.8 \%$ of the total surface area of small corals suppressed growth by $32 \%$ for at least $56 \mathrm{~d}$. Because of its effects on these other life history processes, the regeneration of large surface areas may reduce the fitness of corals to such a degree that it becomes more appropriate to stop regeneration in favour of growth and reproduction.

In addition, the chances of fouling organisms becoming firmly established in lesions increase with time. The regenerating tissue can overgrow filamentous algae which settle already within the first week, but fleshy algae and excavating sponges that settle later appear to require more effort and are often not overgrown at all (authors' pers. obs.) The costs that are associated with removing or killing competitors can be very high (Romano 1990)

The presence of higher than average numbers of lesions on colonies may be indicative of changed environmental conditions. For example, regeneration capability in the main reef-building corals of the Caribbean, Acropora palmata and Montastrea annularis, decreases with increases in sedimentation (Meesters et al. 1992) Consequently, lesions may not be closed and instead become colonized by algae and excavating sponges. The colonization status of these lesions may provide an indication for the time when they were caused, allowing back tracking to certain events in the past. However, because lesion size and number are related to colony size, colony morphology and reef depth (Meesters et al. 1996, 1997), comparisons between communities should be made with great care.

\section{Physiological reasons for limited regeneration capacity}

An exponential decrease in regeneration and an asymptote are obvious in all lesion size classes (Fig. 2), including lesions that were most rapidly closed. This indicates that the speed of regeneration will slow down, regardless whether a lesion will be closed. The reasons for this decrease in the regeneration of lesions in corals have not yet been explored. We hypothesize that they are purely physiological.

Regeneration in this study is measured as lesion closure by new tissue. Initially, this tissue is undiffer- 
entiated, with no polyps or internal structures, and is white, indicating a lack of zooxanthellae to produce energy (Meesters \& Bak 1995). Consequently, new tissue will not be able to produce much energy to contribute to the regeneration of the lesion. Also, for the regeneration process to start, an internal stimulus, e.g. peptide growth factors (Koopmann 1995, Hom 1995) must be produced in the damaged tissue. The production of this stimulus may decrease with time and it may be absent in new tissue. Moreover, as regeneration progresses energy has to be transported through undifferentiated tissue that will take up energy to develop polyps and organs. This will rapidly decreasing the amount of energy that will reach the actual regeneration site.

\section{Conclusions}

We conclude that:

- Tissue regeneration capacity in Montastrea annularis is limited to $4.7 \mathrm{~mm}^{2}$ per mm of lesion perimeter.

- Lesion perimeter length determines the amount of tissue that can be regenerated and, consequently, the shape of a lesion is of more importance than its actual size.

To increase our understanding of the role of regeneration within the life histories of the scleractinian corals, it is crucial to assess this potential in other coral species as well. This will provide insight into the vulnerability of the different species to physical damage, the amount of energy that species have available for regeneration, and the relative importance of regeneration within the life history dynamics of coral species.

Acknowledgements. We thank the Carmabi Institute for providing logistic support, and $\mathrm{O}$. Frans, $\mathrm{F}$ Isabella and $\mathrm{A}$. Thiel for diving and other assistance in the field. We also thank three anonymous reviewers for their comments and suggestions. The research was supported by a grant from the Netherlands Foundation for the Advancement of Tropical Research (WOTRO) W84-311 This is NIOZ publication 3128.

\section{LITERATURE CITED}

Bak RPM (1977) Coral Reefs and their zonation in Netherlands Antilles. Studies Geology 4:3-16

Bak RPM (1983) Neoplasia, regeneration and growth in the reef-building coral Acropora palmata. Mar Biol 77 : $221-227$

Bak RPM, Luckhurst E (1980) Constancy and change in coral reef habitats along depth gradients at Curaçao. Oecologia 47:145-155

Bak RPM, Meesters EH (1996) Coral diversity, populatıons and ecosystem functioning. Proc 6th Int Conf Coelent Biol (in press)

Bak RPM, Steward -van Es Y (1980) Regeneration of superficial damage in the scleractinian corals Agaricia agaricitest pur- purea and Porites astreoldes. Bull Mar Sci 30:883-887

Bythell JC, Gladfelter EH, Bythell M (1993) Chronic and catastrophic natural mortality of three common Caribbean reef corals. Coral Reefs 12:143-152

Connell JH, Keough MJ (1985) Disturbance and patch dynamics of subtidal marine animals on hard substrata. In Pickett STA, White PS (eds) The ecology of natural disturbance and patch dynamics. Academic Press, New York, p 125-151

Fishelson L (1973) Ecological and biological phenomena influencing coral-species composition on the reef tables at Eilat (Gulf of Aquaba, Red Sea). Mar Biol 19:183-196

Hom DB (1995) Growth factors in wound healing. Otolaryngol Clin North Am 28:933-953

Hughes RN (1989) A functional biology of clonal animals. Chapman and Hall, New York, p 321

Hughes TP, Ayre D, ConnelI JH (1992) The evolutionary ecology of corais. Trends Ecol Evol 7:292-295

Hughes TP, Jackson JBC (1980) Do corals lie about their age? Some demographic consequences of partial mortality, fission and fusion. Science 209:713-714

Hughes TP, Jackson JBC (1985) Population dynamics and life histories of tollaceous corals. Erol Monogr 55:141-166

Jackson JBC (1979) Morphological strategies of sessile animals. In: Larwood $G$, Rosen BR (eds) Biology and systematics of colonial organisms. Academic Press, London p 499-555

Jackson JBC, Coates AG (1986) Life cycles and evolution of clonal (modular) animals. Phil Trans R Soc Lond Biol Scl 313:7-22

Knowlton N, Weil E, Weigt LA, Guzman HM (1992) Sibling species in Montastrea annularis, coral bleaching, and the coral climate record. Science 255:330-333

Koopmann CF (1995) Cutaneous wound healing. Otolaryngol Clin North Am 28:835-845

Loya Y (1976) Skeletal regeneration in a Red Sea scleractinian coral population. Nature 261:490-491

Meesters EH, Bak RPM (1993) Effects of coral bleaching on tissue regeneration potential and colony survival. Mar Ecol Prog Ser 96:189-198

Meesters EH, Bak RPM (1994) Regeneration of tissue lesions in corals: a biomonitoring tool? Abstracts 6th Pacific Congress on Marine Science and Technology (PACON). Townsville, p 199

Meesters EH, Bak RPM (1995) Age-related deterioration of a physiological function in the branching coral Acropora palmata. Mar Ecol Prog Ser 121:203-209

Meesters EH, Bos A, Gast GJ (1992) Effects of sedimentation and lesion position on coral tissue regeneration. Proc 7 th Int Coral Reef Symp 2:681-688

Meesters EH, Noordeloos M, Bak RPM (1994) Damage and regeneration: links to growth in the reef-building coral Montastrea annularis. Mar Ecol Prog Ser 112:119-128

Meesters EH, Wesseling I, Bak RPM (1996b) Partial mortality in three species of reef-building corals (Scleractinia) and the relation with colony morphology. Bull Mar Sci 58: $838-852$

Meesters EH, Wesseling I, Bak RPM (1997) Coral colony tissue damage in six species of reef-building corals: partial mortality in relation with depth and surface area. J Sea Res. 27 in press

Romano SL (1990) Long-term effects of interspecific aggression on growth of the reef-building corals Cyphastrea ocellina (Dana) and Pocillophora damicornis (Linnaeus). J Exp Mar Biol Ecol 140:135-146

Sokal RR, Rohlf FJ (1981) Biometry, 2nd edn. WH Freeman and Company, New York 
Sousa WP (1984) The role of disturbance in natural communities. Annu Rev Ecol Syst 15:353-391

Van Duyl FC (1985) Atlas of the living reefs of Curaçao and Bonaire, Netherlands Antilles. Publ Found Sci Res Surinam Neth Antilles 117:1-38

Van Veghel MLJ, Bak RPM (1993) Intraspecific variation of a dominant Carbbean reef building coral, Montastrea annularis: genetic, behavioral and morphometric aspects Mar Ecol Prog Ser 92:255-265

This article was submitted to the editor
Van Veghel MLJ, Bak RPM (1994) Reproductive characteristics of the polymorphic Caribbean reef building coral Montastrea annularis. III. Reproduction in damaged and regenerating colonies. Mar Ecol Prog Ser 109: $229-233$

Von Bertalanffy L (1957) Quantitative laws in metabolism and growth. Q Rev Bio 32:217-231

Wilkinson L (1989) Systat: the system for statistics. Systat, Inc, Evanston, IL

Manuscript first received: October 8,1996

Revised version accepted: December 4, 1996 